\title{
Genetically related Escherichia coli strains associated with Crohn's disease
}

E Masseret, J Boudeau, J F Colombel, C Neut, P Desreumaux, B Joly, A Cortot, A Darfeuille-Michaud

\begin{abstract}
Escherichia coli strains isolated from patients with Crohn's disease (CD) with chronic ileal lesions $(n=14)$, early endoscopic recurrent lesions $(n=20)$, without endoscopic recurrence $(n=7)$, and controls $(n=21)$ were compared by ribotyping. The dendrogram generated by 50 ribotype profile analysis revealed a large cluster of genetically linked $E$ coli strains isolated significantly more frequently from patients with chronic and recurrent CD (24/33 patients) than from controls (9/21) $(\mathbf{p}<0.05)$. Most patients operated on for chronic ileal lesions $(78.5 \%)$ harboured $E$ coli strains belonging to cluster $A(p<0.002$ $v$ controls). The prevalence of patients with early recurrent lesions harbouring $E$ coli strains belonging to this cluster was high but not significant, although 16 strains isolated from eight patients presented the same ribotype profile. In this cluster, 21 of 26 strains isolated from patients with active CD demonstrated adherent ability to differentiated Caco-2 cells, indicating that most of the genetically related strains share a common virulence trait. Comparison of $E$ coli strains recovered from ulcerated and healthy mucosa of patients operated on for CD demonstrated in each patient that a single strain colonised the intestinal mucosa. Our results suggest that although a single $E$ coli isolate was not found in Crohn's ileal mucosa, some genotypes were more likely than others to be associated with chronic or early recurrent ileal lesions.
\end{abstract}

(Gut 2001;48:320-325)

Keywords: Escherichia coli; Crohn's disease; chronic ileal lesion; early endoscopic recurrent ileal lesion; ribotyping

Crohn's disease (CD) is an inflammatory bowel disease of unknown aetiology. Various pathogenic mechanisms have been proposed, including an inflammatory response to a luminal pathogen or an abnormal luminal constituent, autoimmunity, or an abnormal immune response to normal ubiquitous intestinal bacteria or dietary antigens. ${ }^{1}$ Experimental and clinical data incriminate intestinal bacteria or bacterial products in the initiation and perpetuation of chronic intestinal inflammation, characterised by a transmural granulomatous inflammation of discontinuously affected intestinal segments. ${ }^{23}$ Bacterial pathogens have been suggested as aetiological agents in Crohn's disease, such as Mycobacterium paratuberculosis and Listeria monocytogenes, and recent studies have failed to resolve the contentious debate over their contribution in either the initiation or perpetuation of the disease. ${ }^{24}$

The role of luminal bacteria in the pathogenesis of CD is strongly supported by observations that patients with CD clinically improve when luminal bacterial concentrations are decreased. ${ }^{5}{ }^{6}$ Escherichia coli strains are among the bacteria of the luminal flora suspected of being involved in the pathogenesis of CD. It has been shown that $E$ coli antibody titres are higher in patients with CD than in controls. ${ }^{7}$ In addition, immunocytochemistry revealed the presence of $E$ coli antigens in most intestinal resection specimens from patients with $\mathrm{CD}{ }^{8}$ We previously assessed the prominence and virulence of $E$ coli strains associated with the ileal mucosa of patients with CD. ${ }^{9} E$ coli was recovered from $65 \%$ of chronic lesions (resected ileum) and from $100 \%$ of biopsies of early lesions (postoperative endoscopic recurrence). The number of specimens colonised by $E$ coli from early ileal lesions was higher than that from healthy ileal mucosa in patients without endoscopic recurrence of CD and in controls. Furthermore, no difference was observed between chronic ileal lesions and early ileal lesions. We also showed that $E$ coli species were abnormally predominant (50$100 \%$ of the total number of aerobes and anaerobes) in early and chronic ileal lesions of CD. Most of these E coli strains adhered to cultured epithelial cells in vitro, a property that could enable them to colonise the intestinal mucosa. Further studies on the interactions between these strains and cultured human epithelial cells revealed an invasive potential, indicating that a new E coli pathovar might be associated with $\mathrm{CD} .^{10}$

The purpose of this study was to explore the genetic diversity among $E$ coli isolates recovered from the ileal mucosa of 40 patients with $\mathrm{CD}$ and from 21 controls. We performed molecular typing using a DNA probe specifying genes encoding ribosomal ribonucleic acid (rRNA) that are conserved and are therefore good markers of phylogenetic lineage within bacteria and species. ${ }^{11}$ Our aims were: (i) to assess if a particular $E$ coli strain was associated

Abbreviations used in this paper: $\mathrm{CD}$, Crohn's disease; rRNA, ribosomal ribonucleic acid; RT pattern, ribotype pattern; CIL, chronic ileal lesion; ER, early recurrent ileal lesion; $\mathrm{CDH}, \mathrm{CD}$ patient without recurrent lesion; IC, ileal biopsy from control; SC, stool specimen from control. 
with CD; (ii) to examine if particular rRNA gene banding patterns (ribotype profiles or groups of ribotype profiles) were markers of colonising strains involved in either chronic or recurrent ileal lesions in patients with $\mathrm{CD}$; and (iii) to explore the identity of isolates recovered from damaged or healthy mucosa in the same patient.

\section{Materials and methods}

BACTERIAL STRAINS

The $E$ coli strains studied were those which were isolated as dominating strains from ileal biopsy specimens from patients with chronic ileal lesions of CD $(n=14)$, with early endoscopic recurrent ileal lesions $(n=20)$, or without recurrence of the disease $(n=7) .{ }^{9}$ One patient was counted twice because he was operated on for CD (chronic lesion) and presented endoscopic early recurrence after surgery. In seven patients operated on for CD, $E$ coli isolates were recovered from biopsy specimens from both healthy and ulcerated mucosa. The control group included $E$ coli strains isolated from ileal biopsy specimens from patients without inflammatory bowel disease $(n=9)$ or from stool specimens of nonhospitalised healthy individuals belonging to the same age groups as the patients $(n=12)$.

The $E$ coli strains were stored in MuellerHinton broth (Institut Pasteur Production, Marnes-la-Coquette, France) with glycerol $(15 \% \mathrm{v} / \mathrm{v})$ at $-80^{\circ} \mathrm{C}$. Unless otherwise stated, strains were cultured in Luria Bertani broth (Institut Pasteur Production) at $37^{\circ} \mathrm{C}$ for 18-24 hours.

\section{RIBOTYPING}

For each isolate grown in Luria Bertani broth, chromosomal DNA was extracted ${ }^{12}$ and digested with HindIII endonuclease. After electrophoresis in $0.8 \%$ agarose gels (Gibco BRL, Life Technologies, Paisley, Scotland) at $100 \mathrm{~V}$ for five hours in $0.04 \mathrm{M}$ Tris base- $5 \mathrm{mM}$ sodium acetate- 2 mM EDTA (pH 7.9), DNA restriction fragments were Southern blotted onto a nylon membrane (Hybond-N+; Amersham Life Science, UK) and cross linked by exposure for three minutes to UV light.

The $r r n \mathrm{~B} 7$ probe was prepared from a $7.0 \mathrm{~kb}$ restriction fragment that carries the entire $\mathrm{rrn \textrm {B }}$ operon of $E$ coli $\mathrm{K}-12$ and flanking sequences. ${ }^{1314}$ The probe was radiolabelled with a random primer kit (Boehringer Mannheim $\mathrm{GmbH}$, Mannheim, Germany) with $[\alpha-32 P] d C T P$ (Amersham Pharmacia Biotech, UK) and separated from unincorporated nucleotides through a Sephadex G-50 column (Pharmacia BioProcess Technology AB, Uppsala, Sweden). Hybridisation was performed five hours or overnight at $65^{\circ} \mathrm{C}$ in borosilicate tubes (hybridisation chamber; Techne Cambridge) using Rapid-hyb buffer (Amersham). Filters were then washed successively with $0.1 \%$ sodium dodecyl sulphate- $0.3 \mathrm{M} \mathrm{NaCl}-$ $0.03 \mathrm{M}$ Tris sodium citrate dihydrate (one wash at $65^{\circ} \mathrm{C}$ for 20 minutes) followed by $0.1 \%$ sodium dodecyl sulphate-75 $\mathrm{mM} \mathrm{NaCl}-7.5$ $\mathrm{mM}$ Tris sodium citrate dihydrate (four washes at $65^{\circ} \mathrm{C}$ for 15 minutes). The membranes were exposed to Hyperfilm MP film (Amersham) and processed in an automated film developer (Hyper processor; Amersham).

\section{RIBOTYPE ANALYSIS}

For computer analysis, all ribotypes were scanned on a light table using a COHU High Performance CCD camera and digitised by VisioL@b 200 software (Biocom SA). All patterns of restriction fragments were analysed with the Windows version of Phoretix 1D Advanced v4.00 computer program (Phoretix International, Newcastle upon Tyne, UK). The molecular size of each band was calculated from migration distances by "cubic spline" algorithms. The similarities between the patterns were calculated with the Jaccard coefficient (SJ). The proportion of bands common to two strains, $A$ and $B$, was defined as $S J=n A B /(n A+n B-n A B)$, where $n A B$ is the number of bands for $A$ and $B$, respectively. This Jaccard coefficient ranged from 0 to 1.0 , where 1.0 represents $100 \%$ identity (presence and position) for all bands in the two fingerprints being compared. The clustering on a matrix of Jaccard coefficient was based on the unweighted pair group method using arithmetic averages (UPGMA) with the NTSYS-PC Numerical Taxonomy and Multivariate Analysis System (version 1.50- (C), Applied Biostatistics Inc.). This program performed a dendrogram and calculated a similarity coefficient between fingerprints on the basis of band position alone.

INDEX OF DISCRIMINATION

The single numerical index of discrimination (D) or Simpson's index of diversity described by Hunter and Gaston ${ }^{15}$ was used to evaluate the discriminatory power of the typing method. The probability of two unrelated strains being placed into different typing groups was calculated by the following equation: $D=1 \quad(1 / N$ $\left.(N-1) \sum_{j=1}^{s}\right) \quad n_{f}\left(n_{y}-1\right)$, where $N$ is the total number of strains in the sample population, $\Sigma$ is the total number of types described, and $n_{y}$ is the number of strains belonging to the $j^{\text {th }}$ type. This index can be used to evaluate the discriminatory power of ribotyping.

ADHESION TO HUMAN INTESTINAL Caco-2 CELL LINE IN VITRO

Monolayers of differentiated Caco-2 cells were prepared in 24 well Falcon tissue culture plates (ATGC Biotechnologie, Choisy le Grand, France), as previously described. ${ }^{9}$ The cells were seeded at $1 \times 10^{4}$ cells $/ \mathrm{cm}^{2}$ in Dulbecco modified Eagle's medium (Flow Laboratories, Inc., McLean, Virginia, USA) at $37^{\circ} \mathrm{C}$ containing $20 \%$ (vol $/ \mathrm{vol}$ ) fetal bovine serum (Seromed, Berlin, Germany), 1\% L-glutamine (Boehringer Mannheim, Meylan, France), 1\% non-essential amino acids (Boehringer), $100 \mathrm{U} / \mathrm{ml}$ penicillin, $100 \mathrm{mg} / \mathrm{ml}$ streptomycin, and $0.25 \mathrm{mg} / \mathrm{ml}$ amphotericin B (ATGC) at $37^{\circ} \mathrm{C}$ in an atmosphere of $10 \%$ $\mathrm{CO}_{2}$. Monolayers of Caco-2 cells were used at post-confluence after 15 days of culture. Before the adhesion test, cells were washed twice with phosphate buffered saline ( $\mathrm{pH} 7.2$ ). 

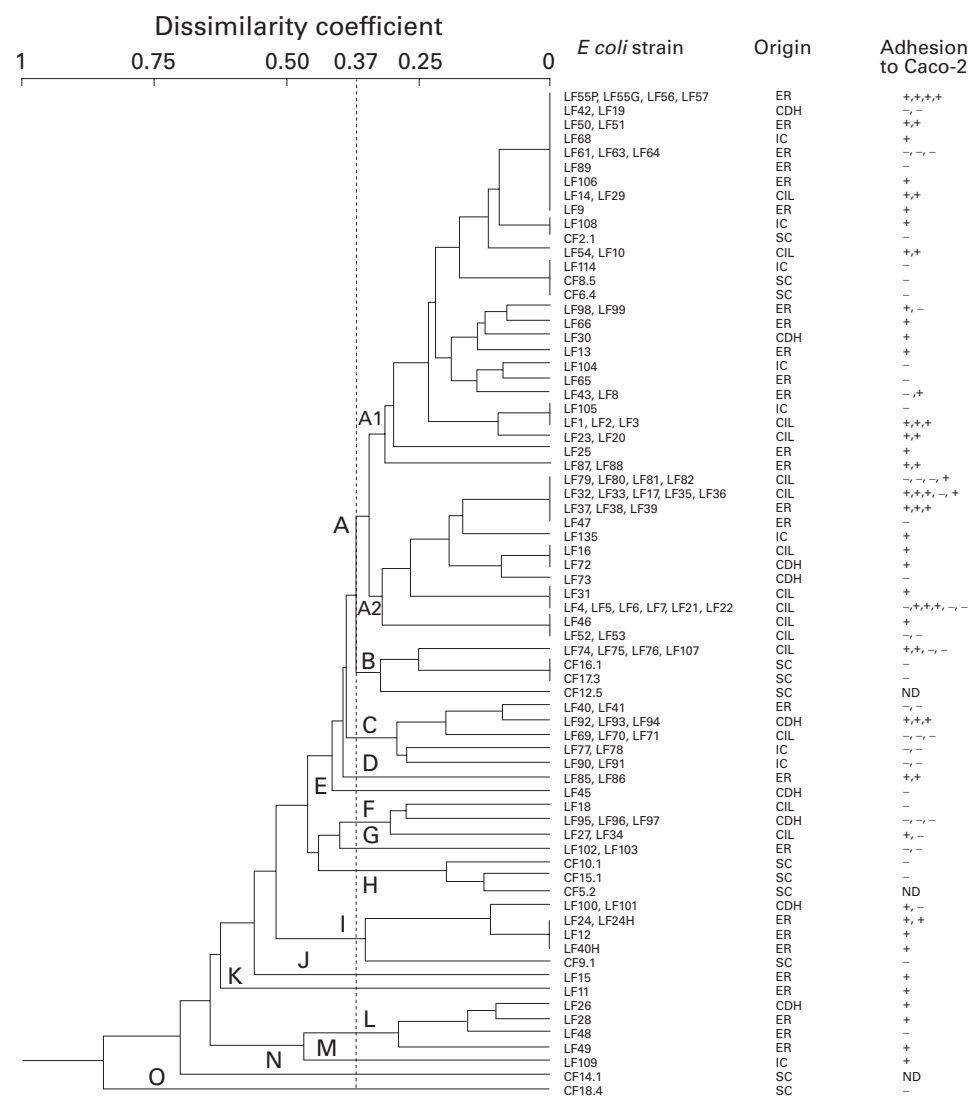

Figure 1 Genetic relationships between Escherichia coli strains, as estimated by clustering analysis of $r R N A$ gene restriction fragment length polymorphism data obtained after DNA digestion by HindIII. The $118 \mathrm{E}$ coli strains analysed were isolated as follows: 41 strains from patients with Crohn's disease (CD) with early recurrent lesions (ER), 39 strains from $C D$ patients with chronic ileal lesions (CIL), 15 strains from CD patients without endoscopic recurrence (CDH), and 23 strains isolated from ileal biopsy (IC) or stool specimens (SC) from controls.

A suspension of $10^{8}$ bacteria/ml in the cell line culture medium, containing $2 \%$ (wt/vol) D-mannose, was added to the tissue culture and incubated for three hours at $37^{\circ} \mathrm{C}$. After three washes with phosphate buffered saline, the cells were fixed with methanol for 10 minutes, stained with $20 \%$ Giemsa for 20 minutes, and examined microscopically under oil immersion. Adhesion assays were performed three times and the mean number of bacteria per cell was determined by examining 200 cells. Adhesion was considered positive if the mean number of bacteria per cell was greater than one.

STATISTICAL ANALYSIS

Data were analysed using the $\chi^{2}$ test unless the variables required a two tailed Fisher exact test. A $p$ value $\leqslant 0.05$ was considered statistically significant.

\section{Results}

The $118 \mathrm{E}$ coli strains analysed were isolated as follows: 41 strains from CD patients with early recurrent lesions (ER), 39 strains from CD patients with chronic ileal lesions (CIL), 15 strains from $\mathrm{CD}$ patients without endoscopic recurrence $(\mathrm{CDH})$, and 23 strains from ileal biopsy (IC) or stool specimens (SC) from controls. Of the 27 patients or controls from whom several isolates were recovered, 19 harboured $E$ coli strains with the same ribotype profile. For a more accurate assessment of the results, we considered only one isolate for each of these 19 subjects. Thus the dendrogram in fig 1 indicating the genetic relationship between $E$ coli strains was made with 71 strains isolated from 40 patients and 21 controls.

\section{DISTRIBUTION OF E COLI STRAINS AMONG} VARIOUS RIBOTYPE PROFILES

Ribotyping of genomic DNA from $E$ coli isolates generated multiple DNA fragments $(5-12)$ in sizes ranging from 1.4 to $26.5 \mathrm{~kb}$. An index of discrimination of greater than 0.95 , the threshold value for interpreting typing results with confidence, was obtained with DNA digestion with the endonuclease HindIII, the $D$ value being 0.978 .

Fifty distinct ribotype profiles (RT patterns) were identified. The 118 strains diverged by up to $85 \%$. At a level of $37 \%$ dissimilarity, 15 RT pattern groups (A-O) were identified. The strains were distributed into eight main clusters (A1, A2, B, C, F, H, I, and L) with 3-27 different isolates each and eight "outliers" (table 1).

The largest was cluster A, composed of two subgroups, A1 and A2, including $E$ coli strains isolated from 26 patients and nine controls, for which 21 ribotype patterns were identified. The subgroup A1 included $E$ coli strains isolated from 18 patients and eight controls, for which 15 ribotype patterns were identified. In this cluster, strains isolated from eight patients and one control presented the same ribotype profile. In cluster A2, which was the second major group, we found $E$ coli strains isolated from 10 patients, for which five ribotype profiles were identified. Twenty nine RT patterns were obtained with the remaining $E$ coli strains isolated from 16 patients and 12 controls and were distributed among clusters B-O (table 1).

\section{RIBOTYPE PATTERNS OF E COLI STRAINS ACCORDING TO THE ORIGIN OF THE ILEAL SPECIMENS}

The distribution of RT patterns according to the origin of the $E$ coli isolates is given in table 2 . In cluster A, $E$ coli strains were isolated from 9/21 controls (42.8\%), 11/14 patients operated

Table 1 Distribution of $E$ coli strains isolated from patients and controls among various ribotype (RT) patterns

\begin{tabular}{|c|c|c|c|c|c|c|c|c|c|c|c|c|c|c|c|c|c|}
\hline \multirow[b]{2}{*}{$R T$ pattern } & \multirow[b]{2}{*}{$\begin{array}{l}\text { Total } \\
\text { (50) }\end{array}$} & \multicolumn{2}{|l|}{$A$} & \multicolumn{14}{|c|}{ Group (No of RT patterns) } \\
\hline & & $\begin{array}{l}A 1 \\
(15)\end{array}$ & $\begin{array}{l}A 2 \\
\text { (6) }\end{array}$ & $B(3)$ & $C(5)$ & $D(1)$ & $E(1)$ & $F(3)$ & $G(1)$ & $H(3)$ & $I(3)$ & $\mathcal{F}(1)$ & $K(1)$ & $L(4)$ & $M(1)$ & $N(1)$ & $O(1)$ \\
\hline No patients/ No isolates & $40^{\mathrm{a}} / 95$ & $18 / 34$ & $10 / 26$ & $1 / 4$ & $3 / 8$ & $1 / 2$ & $1 / 1$ & $3 / 6$ & $1 / 2$ & - & $4 / 6$ & $1 / 1$ & $1 / 1$ & $4 / 4$ & - & - & - \\
\hline No controls/No isolates & $21 / 23$ & $8 / 8$ & $1 / 1$ & $3 / 3$ & $2 / 4$ & - & - & - & - & $3 / 3$ & $1 / 1$ & - & - & - & $1 / 1$ & $1 / 1$ & $1 / 1$ \\
\hline Total of strains & 118 & 42 & 27 & 7 & 12 & 2 & 1 & 6 & 2 & 3 & 7 & 1 & 1 & 4 & 1 & 1 & 1 \\
\hline
\end{tabular}

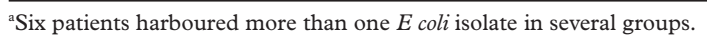


Table 2 Distribution of the 15 ribotype profile groups in relation to the origin of the $E$ coli strain (patients and controls)

\begin{tabular}{|c|c|c|c|c|c|}
\hline & \multicolumn{5}{|c|}{ No patients and controls } \\
\hline & \multirow[b]{2}{*}{$n$} & \multicolumn{4}{|c|}{ Origin of $E$ coli strain } \\
\hline & & $E R^{a}$ & $C I L^{b}$ & $C D H^{c}$ & Controls $^{d}$ \\
\hline A1 & 26 & $12^{\mathrm{e}}$ & 4 & 2 & 8 \\
\hline A2 & 11 & $2^{\mathrm{e}}$ & 7 & 1 & 1 \\
\hline B & 4 & - & 1 & - & 3 \\
\hline $\mathrm{C}$ & 5 & 1 & 1 & 1 & 2 \\
\hline $\mathrm{D}$ & 1 & 1 & - & - & - \\
\hline $\mathrm{E}$ & 1 & - & - & 1 & - \\
\hline $\mathrm{F}$ & 3 & - & 2 & 1 & - \\
\hline G & 1 & 1 & - & - & - \\
\hline $\mathrm{H}$ & 3 & - & - & - & 3 \\
\hline I & 5 & 3 & - & 1 & 1 \\
\hline $\mathrm{J}$ & 1 & 1 & - & - & - \\
\hline K & 1 & 1 & - & - & - \\
\hline $\mathrm{L}$ & 4 & 3 & - & 1 & - \\
\hline M & 1 & - & - & - & 1 \\
\hline $\mathrm{N}$ & 1 & - & - & - & 1 \\
\hline $\mathrm{O}$ & 1 & - & - & - & 1 \\
\hline No patients or controls ${ }^{\mathrm{e}}$ & $61^{\mathrm{f}}$ & $20^{\mathrm{g}}$ & $14^{\mathrm{g}}$ & 7 & 21 \\
\hline
\end{tabular}

${ }^{\mathrm{a}} \mathrm{ER}$, early recurrent ileal lesion; ${ }^{\mathrm{b}} \mathrm{CIL}$, chronic ileal lesion; ${ }^{\mathrm{C}} \mathrm{CDH}$, healthy ileal mucosa from $\mathrm{CD}$ patients without recurrent lesion; ${ }^{d}$ controls, biopsy specimens from patients with noninflammatory bowel disease and stools from healthy nonhospitalised individuals; 'one patient was considered twice because he presented early endoscopic recurrence at two and

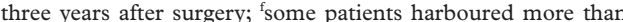
one $E$ coli isolate distributed in several groups; ${ }^{\text {ganother patient }}$ was also considered twice because he was operated on for CD (chronic lesion) and presented early endoscopic recurrence after surgery.

on for chronic ileal lesions $(78.6 \%, \mathrm{p}<0.002)$, $13 / 20$ patients with recurrent ileal lesion $(65 \%$, p $>0.05$ ), and $3 / 7$ patients without recurrence of CD $(42.8 \%)$. A significant difference was observed between the total number of CD patients with chronic and early recurrent lesions and controls harbouring $E$ coli strains

Table 3 Distribution of ribotype profile groups among E coli strains isolated from healthy and ulcerated mucosa of chronic ileal lesions of seven patients

\begin{tabular}{llll}
\hline & & \multicolumn{2}{l}{ No RT pattern-groups (No isolates) } \\
\cline { 3 - 4 } Patient No & No isolates & Healthy mucosa & Ulcerated mucosa \\
\hline 1 & 7 & 16-A2 (3), 34-F (1) & 16-A2 (2), 34-F (1) \\
2 & 3 & $27-\mathrm{C} \mathrm{(1)}$ & $27-\mathrm{C} \mathrm{(2)}$ \\
3 & 4 & $22-\mathrm{B}(1)$ & $22-\mathrm{B}(3)$ \\
4 & 4 & $16-\mathrm{A} 2(2)$ & $16-\mathrm{A} 2(2)$ \\
5 & 2 & $13-\mathrm{A} 1(1)$ & $13-\mathrm{A} 1(1)$ \\
6 & 2 & $21-\mathrm{A} 2(1)$ & $21-\mathrm{A} 2(1)$ \\
7 & 6 & $20-\mathrm{A} 2(4)$ & $20-\mathrm{A} 2(2)$ \\
\hline
\end{tabular}

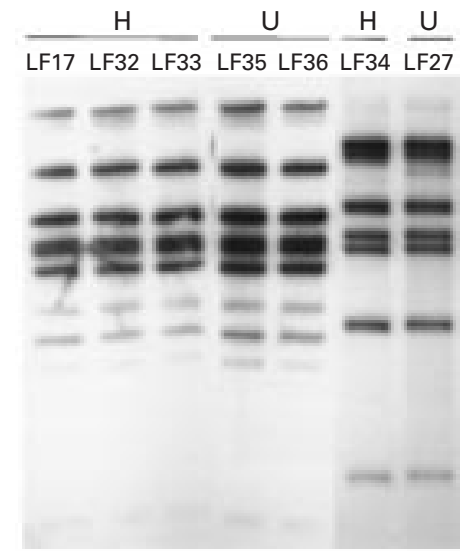

Patient No 1

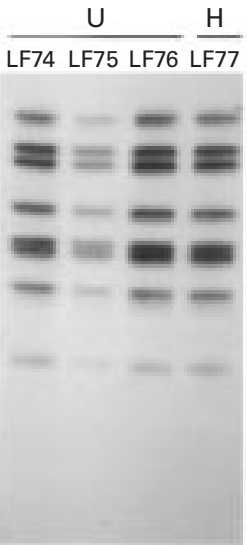

Patient No 2
$-\frac{\mathrm{H}}{\mathrm{LF79} L F 80} \frac{\mathrm{U}}{L F 81 L F 82}$

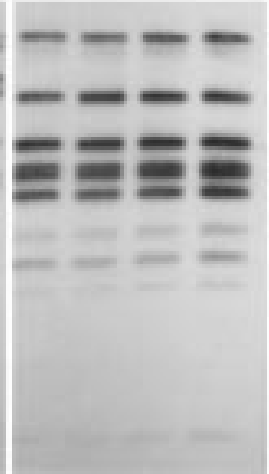

Patient No 4
Figure 2 Ribotype profiles of Escherichia coli strains isolated from healthy and ulcerated mucosa. E coli strains were isolated from healthy $(H)$ and ulcerated $(U)$ mucosa from three patients operated on for Crohn's disease. clustered in group A $(\mathrm{p}<0.05)$. A significant difference was also observed between the number of $\mathrm{CD}$ patients with chronic ileal lesions harbouring $E$ coli belonging to cluster A and controls $(\mathrm{p}<0.03)$.

Patients with chronic ileal lesions harboured $E$ coli strains belonging to A2 (7/14) and A1 (4/14) subclusters. Only one of 21 controls harboured an $E$ coli strain clustered in the A2 group. A significant difference was observed between the number of patients with chronic lesions and the number of controls harbouring $E$ coli strains of cluster A2 $(\mathrm{p}<0.003)$. In contrast, more than half of patients $(12 / 20)$ with early recurrent lesions harboured $E$ coli strains belonging to A1. However, no significant difference was observed between the number of patients harbouring these $E$ coli strains and controls $(\mathrm{p}>0.05)$.

The ability of $E$ coli from CD patients and controls to adhere to differentiated Caco-2 cells is shown in fig 1 . For a more accurate assessment of the results, we considered only one adherent strain when different isolates had the same pattern. Adhesion ability was found for $17(62.9 \%)$ of the $27 \mathrm{E}$ coli strains belonging to subcluster $\mathrm{A} 1$, and nine $(75.0 \%)$ of the $12 \mathrm{E}$ coli strains belonging to subcluster A2. Only $14(48.2 \%)$ of the $29 E$ coli strains tested from all the other clusters were adherent. Of these 14 adherent strains, seven were distributed in two clusters: cluster I, in which four of the five strains were adherent, and cluster $\mathrm{L}$, in which three of the four strains were also adherent. In cluster A, $10(90.9 \%)$ of the $11 \mathrm{E}$ coli strains isolated from patients operated on for chronic ileal lesions, $11(73.3 \%)$ of the 15 strains isolated from patients with recurrent ileal lesions, and three $(33.3 \%)$ of the nine control strains were adherent to Caco- 2 cells.

COMPARISON OF THE RIBOTYPE PATTERN OF $E$ COLI STRAINS ISOLATED FROM HEALTHY OR ULCERATED MUCOSA

This comparison was performed in seven patients operated on for CD in whom $E$ coli strains were isolated from biopsy specimens performed on healthy and ulcerated mucosa. Results are presented in table 3 and ribotype patterns are shown in fig 2 . In all but one patient, the $E$ coli strains isolated from healthy or ulcerated mucosa had the same ribotype, indicating that a single strain colonised the intestinal mucosa. In one patient (patient No 1), $E$ coli isolates belonging to two different ribotypes were isolated from both healthy and ulcerated mucosa.

\section{Discussion}

$E$ coli is the predominant aerobic Gram negative species of the normal intestinal flora where it plays an important role in promoting the stability of the intestinal microbial flora and maintaining the normal intestinal physiology. By acquisition of well known virulence factors, such as production of enterotoxins and cytotoxins, tissue invasion, and adherence to enterocytes, $E$ coli strains become pathogenic and consequently are involved in intestinal diseases (for a review see Nataro and $\mathrm{Kaper}^{16}$ ). 
$E$ coli may also be involved in the pathogenesis of $\mathrm{CD}$, suggesting that $E$ coli strains isolated from patients with inflammatory bowel disease are qualitatively different from those found in normal faeces. ${ }^{2} 9$ 17-19

In this study, ribotyping was used to discriminate $E$ coli strains isolated in patients with CD from those in controls. Ribotyping has been demonstrated to be a useful method for examining similarity in isolates that are separated in time or space. ${ }^{20}$ Restriction endonuclease HindIII was used as recommended by many authors to perform $E$ coli ribotyping. ${ }^{21-24}$ The dendrogram generated by ribotyping revealed a large A cluster of genetically linked $E$ coli strains isolated more frequently from patients with chronic or recurrent $\mathrm{CD}$ than from controls $(\mathrm{p}<0.05)$. In this cluster, we found $E$ coli strains isolated from 11/14 patients operated on for chronic ileal lesions $(78.5 \%)$ and from $13 / 20$ patients with recurrent ileal lesions $(65 \%)$. Most patients operated on for chronic ileal lesions harboured $E$ coli strains belonging to cluster A $(p<0.002)$. This distribution was significantly different from that of controls $(p<0.03)$. In contrast, the prevalence of patients with early recurrent lesions harbouring $E$ coli strains belonging to this cluster was high. However, the difference between patients and controls was not significant ( $\mathrm{p}>0.05)$ as $E$ coli strains from seven patients were distributed in seven other different ribotype clusters.

Cluster A can be divided into two subclusters, A1 and A2. Of the E coli strains isolated from 13 patients with early recurrent lesions of CD, strains from $12(85.2 \%)$ patients were distributed in subcluster A1. In addition, $E$ coli strains isolated from eight patients with early recurrent lesions presented the same ribotype profile. Thus although $E$ coli strains associated with early recurrent lesions were widely distributed in the dendrogram, some strains presented either the same or a very close ribotype profile belonging to the same cluster. This may indicate the existence of genetically linked $E$ coli strains.

Patients with chronic ileal lesions harboured $E$ coli strains belonging to both subcluster A1 (4/14) and subcluster A2 (7/14). Compared with controls, the distribution of $E$ coli strains isolated from chronic ileal lesions in subcluster A2 was significant $(p<0.003)$. Thus $50 \%$ of patients with chronic lesions of CD had $E$ coli that were genetically related. The main difficulty with bacterial analysis of chronic lesion biopsy specimens is that luminal bacteria may secondarily colonise the ulcerated mucosa. Bacteria may adhere to a damaged mucosal surface through increased exposure of receptors or through non-specific interactions between bacterial proteins and the mammalian extracellular matrix. ${ }^{25} \mathrm{E}$ coli strains associated with chronic lesions that were not genetically related could correspond to second invaders belonging to normal endogenous flora. We have shown that some $E$ coli strains isolated from chronic lesions of patients with CD synthetised Pap and/or Sfa and/or Dr adhesins, also found in strains associated with urinary tract infections. ${ }^{9}$ The presence of these strains in CD patients could therefore reflect the persistence of potential uropathogenic $E$ coli belonging to the endogenous flora.

$E$ coli strains were compared in seven patients operated on for CD. Analysis was performed on biopsy specimens corresponding to healthy and ulcerated mucosa. For each of the seven patients tested, the $E$ coli strains presented the same ribotype profile, regardless of the state of the mucosa, indicating uniform colonisation of the healthy and ulcerated mucosa by the same strain(s). A similar observation was reported by Giaffer and colleagues ${ }^{17}$ who found that adhesive $E$ coli strains were as frequently isolated during acute exacerbations of CD and ulcerative colitis as when the disease was quiescent. This is consistent with the notion that altered glycoproteins or glycolipids on the intestinal mucosa may represent receptors for specific adhesins harboured by $E$ coli associated with $\mathrm{CD}^{26}{ }^{27}$ If such a hypothesis is correct, these receptors are likely to be expressed uniformly on the intestinal mucosa.

The aim of our study was to determine if a particular $E$ coli strain was involved either in the initiation or perpetuation of CD. It was not possible to identify a unique $\mathrm{CD}$ associated $E$ coli strain. Some patients with early recurrence of CD harboured $E$ coli strains that were genetically linked as they presented an identical ribotype profile or belonged to a common cluster of ribotype patterns. In addition, $50 \%$ of patients with chronic lesions harboured genetically related $E$ coli strains. Thus some genotypes were more likely than others to be associated with chronic or early recurrent ileal lesions of $\mathrm{CD}$.

A correlation between particular evolutionary lineages and putative virulence factors is possible in that these $E$ coli strains would be involved in the initiation of lesions by expressing common virulence factors such as adhesive properties to the intestinal mucosa. Analysis of the ability of the genetically related $E$ coli strains of cluster A to adhere to differentiated Caco-2 intestinal cells indicated that $90.9 \%$ of the $E$ coli strains isolated from patients operated on for chronic ileal lesions and $73.3 \%$ of strains isolated from patients with recurrent ileal lesions were adherent. In contrast, among the $E$ coli strains isolated from biopsy or stool specimens of controls also belonging to cluster A, only $33.3 \%$ exhibited adhesion ability. These results indicate that the ability to adhere to intestinal cells is a common virulence factor harboured by most of the genetically related $E$ coli strains isolated from patients with active CD.

Most studies have focused on the phenotypic characterisation of $E$ coli isolated from CD patients or on the characterisation of previously described virulence factors encoding genes. ${ }^{17} 182829$ This study shows the existence of $E$ coli strains that may have evolved from the same ancestral strain, perhaps by acquisition of additional virulence factors via gene transfer or insertion of a pathogenicity island(s) in the bacterial chromosome. These changes would increase the pathogenicity of some $E$ coli strains and therefore lead to the colonisation of the 
intestinal mucosa of patients with $\mathrm{CD}$ by particular $E$ coli strains. Further work using molecular studies based on DNA mapping of insertional DNA sequences present in $E$ coli strains associated with $\mathrm{CD}$ but absent in $E$ coli strains isolated from healthy individuals is needed to identify potentially unknown virulence determinants.

This study was supported by grants from Association F Aupetit, Fonds de Recherche de la Societé Nationale Française de Gastro-Entérologie, Institut de Recherche sur les Maladies de 1'Appareil Digestif (IRMAD, Laboratoires Astra, France), Centre Hospitalier Régional Universitaire de Lille (contract 96/38/9713 and PHRC 97), Ministère de la Recherche et de la Technologie (EA2148), and INSERM CRI 4U004B. Jérôme Boudeau was supported by a fellowship from IRMAD. The excellent assistance of Christophe De Choms for statistica excellent assistance of Christophe De Champs for statistica acknowledged. We also thank Chantal Rich for technical assistance. We thank Valérie Livrell and Christiane Forestier for helpful discussion and critical reading of the manuscript.

1 Sartor RB. Enteric microflora in IBD: pathogens or commensals? Inflamm Bowel Dis 1997;3:230-5.

2 Sartor RB. Microbial agents in the pathogenesis, differential diagnosis, and complications of inflammatotry bowel
diseases. In: Blaser J, Smith PD, Ravdin JI, et al. Infections of diseases. In: Blaser J, Smith PD, Ravdin JI, et al. Infections of the gast

3 Rutgeerts P, Geboes K, Vantrappen G, et al. Predictability of the postoperative course of Crohn's disease. Gastroenterol ogy 1990;99:956-63.

4 Bulois P, Desreumaux P, Neut C, et al. Infectious agents and Crohn's disease. Clin Microbiol Infect 1999;5:601-4.

5 Sutherland L, Singleton J, Sessions J. Double blind, placebo controlled trial of metronidazole in Crohn's disease. Gut 1991;32:1071-5.

6 Wellmann W, Fink PC, Benner F. Endotoxemia in active Crohn's disease. Treatment with whole gut irrigation and 5-aminosalicylic acid. Gut 1986;27:814-20.

7 Tabaqchali S, O'Donoghue DP, Bettelheim KA. Escherichia coli antibodies in patients with inflammatory bowel disease. coli antibodies in patients

8 Cartun RW, Van Kruiningen HJ, Pedersen CA, et al. An Cartun RW, Van Kruiningen HJ, Pedersen CA, et al. An immunocytochemical search for infectio

9 Darfeuille-Michaud A, Neut C, Barnich N, et al. Presence of adherent Escherichia coli strains in ileal mucosa of patients with Crohn's disease. Gastroenterology 1998;115 1405-13

10 Boudeau J, Glasser AL, Masseret E, et al. Invasive ability of an Escherichia coli strain isolated from the ileal mucosa of a patient with Crohn's disease. Infect Immun 1999;67:4499509.

11 Maynard Smith J, Smith NH, O'Rourke M, et al. How clonal are bacteria? Proc Natl Acad Sci USA 1993;90:4384-
12 Picard-Pasquier N, Ouaged M, Picard B, et al. A simple, sensitive method of analysing bacterial ribosomal DNA polymorphism. Electrophoresis 1989;10:186-9.

13 Alos JI, Lambert T, Courvalin P. Comparison of two molecular methods for tracing nosocomial transmission of Escherichia coli $\mathrm{K} 1$ in a neonatal unit. f Clin Microbiol 1993; 31:1704-9.

14 Brosius J, Ullrich A, Raker MA, et al. Construction and the fine mapping of recombinant plasmids containing the $\mathrm{rrnB}$ ribosomal RNA operon of E. coli. Plasmid 1981;6:112-18.

15 Hunter PR, Gaston MA. Numerical index of the discriminatory ability of typing systems: an application of Simpson's index of diversity. F Clin Microbiol 1988;26: 2456-66.

16 Nataro JP, Kaper JB. Diarrheagenic Escherichia coli. Clin Microbiol Rev 1998;11:142-201.

17 Giaffer $\mathrm{MH}$, Holdsworth CD, Duerden BI. Virulence properties of Escherichia coli strains isolated from patients with inflammatory bowel disease. Gut 1992;33:646-50.

18 Burke DA, Axon ATR. Adhesive Escherichia coli in inflammatory bowel disease and infective diarrhoea. BMf 1988;297:102-4.

19 Dickinson RJ, Varian SA, Axon ATR, et al. Increased incidence of faecal coliforms with in vitro adhesive and invasive properties in patients with ulcerative colitis. Gut invasive properties

20 Marshall S, Clark CG, Wang G, et al. Comparison of molecular methods for typing Vibrio parahaemolyticus. $\mathcal{F}$ Clin Microbiol 1999;37:2473-8.

21 Parveen S, Portier KM, Robinson K, et al. Discriminant analysis of ribotype profiles of Escherichia coli for differentiating human and nonhuman sources of tion of diarrhoeagenic Escherichia coli clones by ribotyping and ERIC-PCR. $₹$ Med Microbiol 1998;47:227-34.

23 Tarkka E, Ahman H, Siitonen A. Ribotyping as an epidemiologic tool for Escherichia coli. Epidemiol Infect 1994;112:263-74.

24 Bingen EH, Denamur E, Picard B, et al. Molecular epidemiology unravels the complexity of neonatal Escherichia coli acquisition in twins. F Clin Microbiol 1992;30: 1896-8.

25 Westerlund B, Korhonen TK. Bacterial proteins binding to the mammalian extracellular matrix. Mol Microbiol 1993;9: 687-94.

26 Rhodes JM. Unifying hypothesis for inflammatory bowel disease and associated colon cancer. Lancet 1996;347:40-4.

27 Tysk C, Riedesel H, Lindberg E, et al. Colonic glycoproteins in monozygotic twins with inflammatory bowel disease. Gastroenterology 1991;100:419-23.

28 Schultsz C, Moussa M, van Ketel R, et al. Frequency of pathogenic and enteroadherent Escherichia coli in patients with inflammatory bowel disease and controls. 7 Clin Pathol 1997:50:573-9.

29 Shen W, Steinrück H, Ljungh A. Expression of binding of plasminogen, thrombospondin, vitronectin, and fibrinogen, and adhesive properties by Escherichia coli strains isolated from patients with colonic diseases. Gut 1995;36: $401-6$ 